\title{
An arteriovenous loop in a protected space generates a permanent, highly vascular, tissue-engineered construct
}

\author{
Zerina Lokmic,* Filip Stillaert, ${ }^{\dagger}$ Wayne A. Morrison,* Erik W. Thompson,* \\ and Geraldine M. Mitchell*,1 \\ *Bernard O'Brien Institute of Microsurgery and University of Melbourne Department of Surgery, St. \\ Vincent's Hospital, Melbourne, Australia; and ${ }^{\dagger}$ Department of Plastic and Reconstructive Surgery \\ Unit, University Hospital, UZ Gent, Belgium
}

ABSTRACT A major obstacle to 3-dimensional tissue engineering is incorporation of a functional vascular supply to support the expanding new tissue. This is overcome in an in vivo intrinsic vascularization model where an arteriovenous loop (AVL) is placed in a noncollapsible space protected by a polycarbonate chamber. Vascular development and hypoxia were examined from 3 days to 112 days by vascular casting, morphometric, and morphological techniques to understand the model's vascular growth and remodeling parameters for tissue engineering purposes. At 3 days a fibrin exudate surrounded the AVL, providing a scaffold to migrating inflammatory, endothelial, and mesenchymal cells. Capillaries formed between 3 and 7 days. Hypoxia and cell proliferation were maximal at 7 days, followed by a peak in percent vascular volume at 10 days $(23.20 \pm 3.14 \%$ compared with $3.59 \pm 2.68 \%$ at 3 days, $P<0.001)$. Maximal apoptosis was observed at 112 days. The protected space and spontaneous microcirculatory development in this model suggest it would be applicable for in vivo tissue engineering. A temporal window in a period of intense angiogenesis at 7 to 10 days is optimal for exogenous cell seeding and survival in the chamber, potentially enabling specific tissue outcomes to be achieved.-Lokmic, Z., Stillaert, F., Morrison, W. A., Thompson, E. W., Mitchell, G. M. An arteriovenous loop in a protected space generates a permanent, highly vascular, tissue-engineered construct. FASEB J. 21, 511-522 (2007)

Key Words: chamber space $\cdot$ macrovascular loop $\cdot$ angiogenesis $\cdot$ growth and remodeling • in vivo tissue engineering

A CHRONIC SHORTAGE OF LIVING AND CADAVERIC donor organs and an increase in the number of patients waiting for organ transplants (1) have instigated a search for alternative sources of functional tissues and organs. Recent advances in tissue-engineered products used clinically include cartilage (2), skin (3), urethra (4), and blood vessels $>5 \mathrm{~mm}$ in diameter (5). The success of these products in vivo is due mainly to their small 2-dimensional volume or avascular nature, which permits them to survive in vivo implantation. Subsequent ingrowth of capillaries from the recipient site vessels nourishes these constructs. This has been termed extrinsic vascularization. Although moderately successful, this technique relies on using minute construct combinations of cells and extracellular matrix (ECM) that must survive on diffusion prior to ingrowth of capillaries. Permanent, large, independent constructs grown under these conditions are yet to be created.

An alternative to extrinsic vascularization is an intrinsic approach. Intrinsic vascularization is utilized in a novel tissue-engineering construct in which a macrovascular arteriovenous shunt loop (AVL) is enclosed in an isolated protected space created by a polycarbonate chamber. Spontaneous new tissue growth without the addition of extracellular matrices or growth factors has been observed in this construct (6).

The advantages of the AVL model for tissue engineering purposes include the following: 1) the rigid noncollapsible chamber walls create a large permanent space in which new tissue and vasculature can expand; the chamber allows rapid localization, manipulation, and retrieval of the construct at any time, and chamber shape and size can be varied according to tissue requirements; and 2) as the contents of the chamber are contained, timed delivery of specific cell populations, growth factors, matrices, or differentiation agents could ultimately direct specific tissue or organoid outcomes in this model.

Although the AVL chamber model possesses a number of highly desirable tissue engineering properties, the characteristics of its microcirculatory growth, remodeling, and permanency are unknown.

Angiogenesis, the formation of new capillaries, arterioles, and venules from endothelial cells (ECs), smooth muscle cells (SMCs), and/or pericytes, is necessary for the formation of a microcirculatory network

\footnotetext{
${ }^{1}$ Correspondence: Bernard O'Brien Institute of Microsurgery, 42 Fitzroy St., Fitzroy, 3065, Melbourne, Victoria, Australia. E-mail: mitcg@unimelb.edu.au

doi: 10.1096/fj.06-6614com
} 
(7) in viable tissue-engineered constructs. The role of blood-borne endothelial precursor cells in the formation of tissue-engineered microcirculatory networks is so far undetermined, but it is probable that this mechanism plays some role in tissue-engineered microcirculatory development $(8,9)$.

In vitro creation of engineered microcirculatory networks has had some success (10-12), but there are significant design restrictions in expanding these constructs for large 3-dimensional tissue engineering required in clinical settings (13).

Although many in vivo tissue engineering studies have reported extrinsic capillary growth into their constructs, usually in response to specific angiogenic growth factor administration (14-16) and quantitation of vascularity at a single short-term time point $(17,18)$, few studies, with the exception of Koike et al. (19), have included a quantitative temporal study of vascular development and remodeling in an in vivo tissue engineering construct.

In this study, the main aim was to determine the extent, growth characteristics, and remodeling of the naturally occurring, intrinsically generated blood vessel network of AVL constructs grown in polycarbonate chambers. Understanding this phenomenon is crucial to further exploitation of this model for tissue engineering, especially for the targeted delivery of cells to maximize their survival.

Blood vessel development in this engineered microcirculation was assessed over a 112 day (16 wk) time frame, histologically, immunohistochemically, and by transmission electron microscopy (TEM), to identify cells initially invading the chamber and giving rise to a new microcirculatory bed. Vascular casting, hypoxyprobe-1 labeling, proliferative and apoptotic cell studies, and morphometry were then employed to characterize vascular growth and remodeling.

\section{MATERIALS AND METHODS}

\section{Animals}

Six male Sprague-Dawley rats (ARC, Perth, Western Australia) weighing between 280 and $320 \mathrm{~g}$ were used per time point group (3, 7, 10, 14, 21, 28, 42, 56, and 112 days). Another two rats were included in the $3,7,10$, and 14 day groups for vascular casting and two additional rats at the 7 day time point were used for TEM. All experimental and medical procedures were approved by the Animal Ethics Committee of St. Vincent's Hospital (34/02), Melbourne, Australia, and were conducted in accordance with the Australian National Health and Medical Research Council guidelines for the care and maintenance of animals.

\section{Creation of the AVL chamber model and harvest of the in vivo engineered AVL construct}

Rats were anesthetized with intraperitoneal (i.p.) phenobarbitone $(30 \mathrm{mg} / \mathrm{kg})$. Under sterile conditions the femoral vessels of both legs were exposed between the inguinal ligaments proximally and the bifurcation of the saphenous and popliteal vessels distally. An $11 \mathrm{~mm}$ vein graft was dissected from the left femoral vein and placed in sterile heparinized saline. The right femoris artery and vein were exposed, the profunda femurus artery and vein tied, and the right superior epigastric artery and vein were dissected and ligated $\sim 10 \mathrm{~mm}$ from their femoral vessel origin. The right femoral artery and vein were cut distal to the epigastric branches and the vein graft was interposed with microanastomoses to create an AVL. The base of a sterile polycarbonate chamber (Fig. 1A) (Department of Chemical and Biomolecular Engineering, University of Melbourne, Australia) was placed under the AVL (Fig. 1B) and sutured through openings in the base into the underlying muscle fascia. The ligated right superficial epigastric artery and vein were used to anchor the AVL to the chamber as they were caught at the edges of the chamber when the lid was closed over the base. The opposed edges of the wounds were sutured together and the animals were resuscitated.

Three, $7,10,14,21,28,42,56$, or 112 days after chamber implantation, the rats were anesthetized with phenobarbitone $(30 \mathrm{mg} / \mathrm{kg})$, then the chamber tissue was harvested once the artery and vein of the AVL were checked for patency. Constructs were removed by tying off the AVL vessels $5 \mathrm{~mm}$ proximal to the chamber entrance. After weighing and volume displacement measurements (20), the tissue was immersion fixed in $4 \%$ paraformaldehyde (PFA), cut into $1 \mathrm{~mm}$ thick vertical slices, and processed for routine histology and immunohistochemistry. Animals were euthanized by i.p. injection of Lethobarb ${ }^{\circledR}(200 \mathrm{mg} / \mathrm{kg}$, Virbac, Peakhurst, Australia).

\section{Identification of cellular populations invading the chamber} constructs

Paraffin-embedded $3 \mu$ m-thick sections were cut from all blocks at every time point and stained with hematoxylin and eosin, toluidine blue, and Mason's trichrome to examine the overall tissue and vessel morphology within the construct.

To identify the cell phenotypes that first invade the fibrin matrix, the following antibodies were used: anti-c-kit (c-19; Santa Cruz Biotechnology, Inc., Santa Cruz, CA, USA), Thy-1 (PharMingen International, San Diego, CA, USA), VEGFR-2 [also known as Flk-1 (AF 644, R\&D Systems Minneapolis, MN, USA) ], $\alpha$-smooth muscle actin ( $\alpha$-SMA), desmin (clone D33), both purchased from Dakocytomation, Carpinteria, CA, USA, and a macrophage marker, ED-1 (MCA341, Serotec, Oxford, UK). Tissue sections were dewaxed and treated in $0.1 \mathrm{M}$ citric acid where required (c-kit, desmin). The sections were then washed in PBS, pH 7.5, and treated with $3 \% \mathrm{H}_{2} \mathrm{O}_{2}$ in methanol for 10 min to block endogenous peroxidase. After another wash in PBS, the sections were incubated for $20 \mathrm{~min}$ in $10 \%$ goat (for $\alpha$-SMA, Thy-1, ED-1, and desmin) or rabbit serum (for c-kit and VEGFR-2), followed by an overnight incubation in primary antibody at $4^{\circ} \mathrm{C}$ at dilutions of: c-kit, 1:100; Thy-1, and ED-1, 1:1000; and desmin, 1:250. $\alpha$-SMA was used at 1:400 dilution for $1 \mathrm{~h}$ at room temperature. The primary antibody was detected using secondary antibodies: biotinylated goat anti-mouse (for $\alpha$-SMA, ED-1, desmin, and Thy-1) or goat anti-rabbit (for VEGFR-2) at 1:400 dilution and rabbit anti-goat horseradish peroxidase (HRP) antibody (for c-kit) at 1:200 for $30 \mathrm{~min}$ at room temperature. All secondary antibodies were purchased from Dakocytomation. The biotinylated complexes were detected using streptavidin-HRP (1:400; Dakocytomation) and visualized with 3'3-diaminobenzidine $\left(3,3^{\prime}\right.$ diaminobenzidine) (Dakocytomation). The negative controls included substitution of a primary antibody with a corresponding serum isotype. 

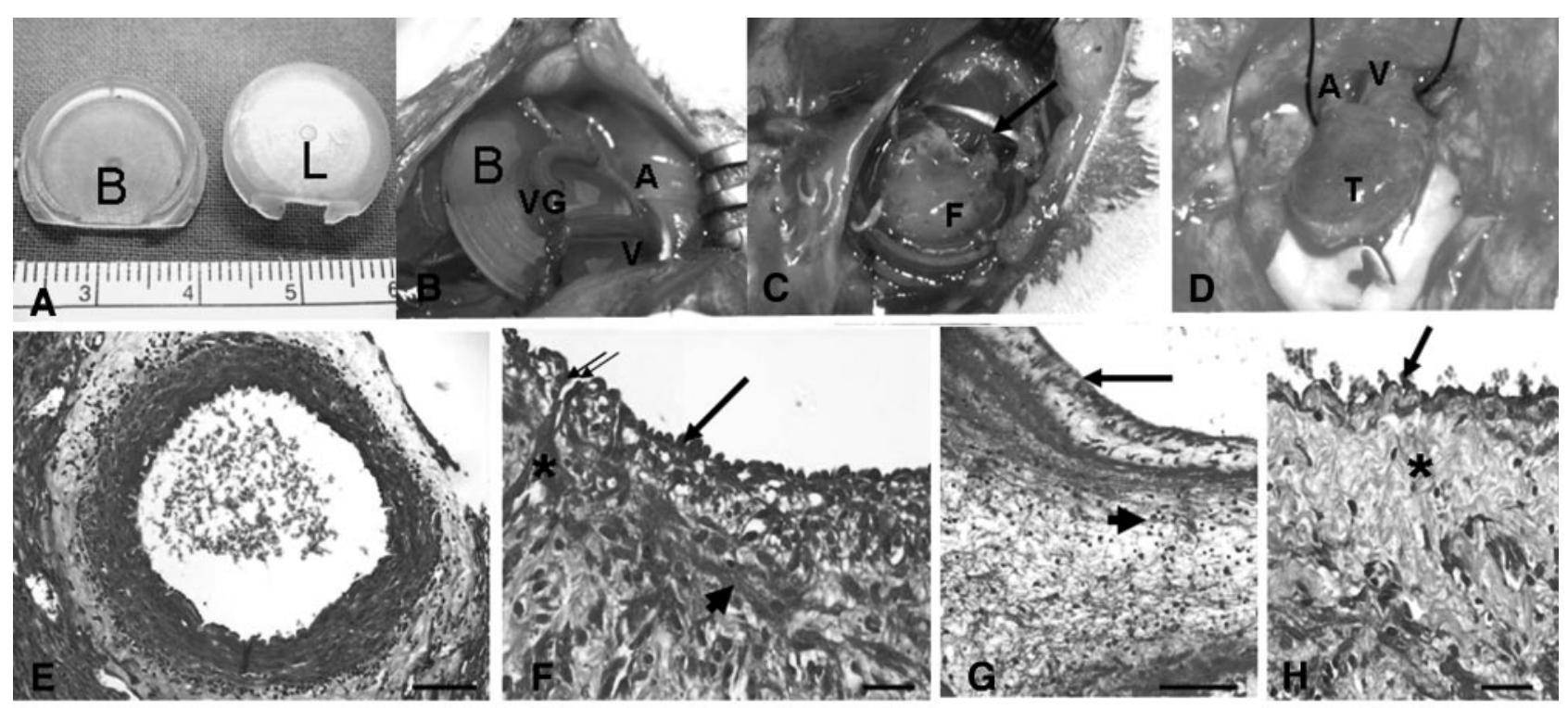

I Weight of AVL constructs
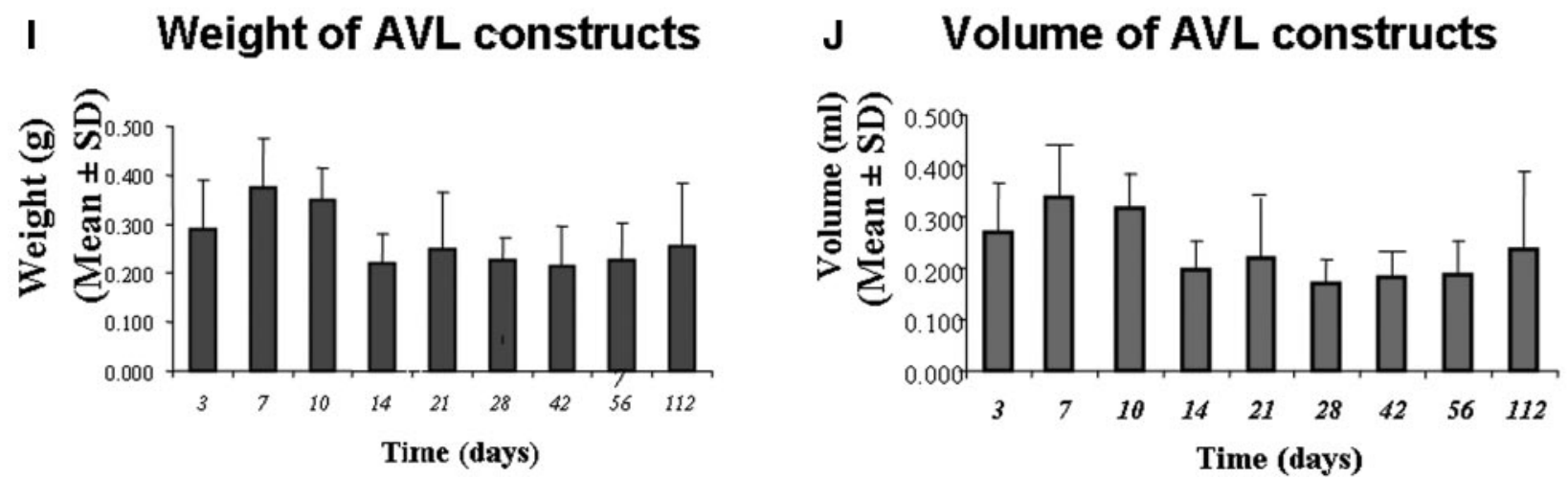

Figure 1. $A-D$ ) Macroscopic views of chamber construct. A) Polycarbonate chamber base (B) and chamber lid (L), B) The AVL positioned on the chamber base (B) prior to closing the chamber lid. A, femoral artery; VG, vein graft, V, femoral vein components of the AVL. C) The chamber lid removed from a 3 day construct. Note the large amount of fibrin (F) covering the AVL. Arrow indicates where the femoral artery and vein enter and leave the construct. D) A 112 day construct. A flap of healthy tissue (T) covers the AVL, which is obscured. The femoral artery (A) and vein (V) entering and leaving the construct are visible. $E-H)$ AVL histology. E) Femoral artery in a 7 day construct. Scale bar $=100 \mu \mathrm{m}$. F) Femoral vein wall: medial SMCs have disappeared, while the endothelial surface has a "piled up" appearance (large arrow). Large mesenchymal cells are evident in the wall (arrowhead). Similar cells appear to be forming capillaries (asterisk), one of which is seen connecting to the vein lumen (double arrow). Scale bar $=20 \mu \mathrm{m}$. $G$ ) The vein graft wall at 3 days. Arrow indicates luminal surface without endothelium. Inflammatory cells (arrowhead) are evident in the surrounding fibrin. Scale bar $=100 \mu \mathrm{m}$. H) Endothelial coverage (arrow) on the luminal surface of the vein graft at 7 days. Note the relatively acellular nature of the graft wall (asterisk). Scale bar $=20 \mu \mathrm{m}$. $I, J)$ Weight and volume of constructs to 112 days. $I$ ) The mean weight (g) ( $\pm \mathrm{SD}$ ) of all constructs at each harvest time point.. $J)$ The mean displacement volume $(\mathrm{ml})( \pm \mathrm{SD})$ of all constructs at each harvest time point.

\section{Transmission electron microscopy}

Two rats with 7 day AVL chambers were anesthetized, the abdominal cavity was opened, and heparin (300 U/kg) was injected into the vena cava $5 \mathrm{~min}$ before cannulation of the femoral artery. The construct was perfused with sodium cacodylate buffer, $\mathrm{pH} 7.4\left(37^{\circ} \mathrm{C}\right.$, at $\left.100 \mathrm{mmHg}\right)$ for $5 \mathrm{~min}$, followed by Karnovsky's fixative (21). The construct was removed, cut into 1 mm-thick slices, placed in Karnovsky's fixative overnight at $4^{\circ} \mathrm{C}$, followed by sodium cacodylate buffer overnight. Tissue slices were further cut into $1 \mathrm{~mm} \times 2 \mathrm{~mm}$ tissue blocks (the position around the AVL noted) and transferred into $2 \%$ osmium tetroxide for $1 \mathrm{~h}$, followed by distilled water washes and $2 \%$ uranyl acetate in $70 \%$ acetone solution for $20 \mathrm{~min}$ prior to dehydration through graded acetone and routine processing into Spurr's resin and polymerization. The resin-embedded tissue was cut into $1 \mu \mathrm{m}$ sections and stained in $1 \%$ toluidine blue. Suitable tissue blocks determined from light microscopic examination were cut at $70-90 \mathrm{~nm}$, then stained in $2 \%$ uranyl acetate and Reynold's lead/citrate solution. The sections were viewed and photographed on a SIEMENS 102 electron microscope at $60 \mathrm{KV}$.

\section{Vascular casting}

To macroscopically visualize AVL blood vessel development, two additional rats per group at $3,7,10$, and 14 days were surgically prepared as for TEM and the constructs were perfused with PBS $\left(37^{\circ} \mathrm{C}\right.$, at $\left.100 \mathrm{mmHg}\right)$, followed by $4 \%$ PFA $\left(37^{\circ} \mathrm{C}\right)$ for $5 \mathrm{~min}$. Resin (Mercox Kit, Ladd Research, Burlington, VT, USA) was prepared per the manufacturer's instructions and infused through the same cannula until the onset of polymerization. The construct was then removed and 
immersed in hot water $\left(50^{\circ} \mathrm{C}\right)$ for $1 \mathrm{~h}$ to complete resin curing. The surrounding tissue was removed by maceration in alternating rinses of $5 \%$ potassium hydroxide and distilled water (22).

\section{Hypoxia studies}

Two animals per group (3-28 days) were injected with 100 $\mathrm{mg} / \mathrm{kg}$ of pimonidazole hydrochloride (hypoxyprobe- 1 , Hypoxyprobe $^{\mathrm{TM}}$, Natural Pharmacia International, Inc., Belmont, MA, USA) via the tail vein, as described previously (23). A sample of liver tissue was collected as a positive control. Negative control tissue consisted of liver and construct tissues from hypoxyprobe-1-free animals. The negative control for the immunohistochemistry consisted of omission of a primary antibody from the reaction.

\section{Proliferation studies}

To detect proliferating cells, sections were stained with Ki67 (24), viewed under $\times 40$ magnification, and the image was captured via a digital video camera (JVC, TK C1480E) attached to the microscope. The entire tissue area was outlined and the area was measured. A series of fields within that area was then randomly and systematically sampled so that $5 \%$ of total area of the tissue was counted using an electronic stepping stage (H128, Prior Scientific, Rockland, USA) and the Computer Assisted Stereological Toolbox (CAST System, Olympus, Denmark), then expressed as mean number of proliferating cells $/ \mathrm{mm}^{2} \pm \mathrm{sEM}$. Rat intestine was used as the positive control tissue.

\section{TUNEL assay}

Apoptotic cells in paraffin sections were detected as previously reported (25) and counted as described for proliferating cells. Rat lymph node was used as positive control tissue. Hemosiderin-filled macrophages (26) were also TUNEL-positive; however, their staining pattern was vacuole-like, reflecting the remnant phagocytosed DNA. These cells were easily distinguished from other apoptotic cells due to the refractive nature of hemosiderin and were excluded from the apoptotic cell count.

\section{Immunohistochemical demonstration of blood vessels and morphometric determination of tissue components in AVL constructs}

Construct tissue sections were stained immunohistochemically with Bandeiraea Simplicifolia lectin (Vector Laboratories, Burlingame, CA, USA) (23) to identify blood vessels. The negative control consisted of the omission of the B. Simplicifolia lectin from the reaction. To determine the percent volume density of tissue components, stained sections were viewed under $\times 20$ magnification with a test grid eyepiece lens placed over the sections. A random microscopic field was selected as a starting point and every fifth field was counted. Tissue categories counted were the AVL, fibrin matrix, connective tissue, and blood vessel components of the constructs. To determine percent volume of a tissue component, the number of points counted for the individual component was divided by the total number of points counted per section and expressed as a percentage (27).

The vascular volume density within the new connective tissue compartment was determined by counting the number of points falling over a vessel (other than the AVL) divided by the sum of points falling on new blood vessels and connective tissue. This figure was then expressed as a percentage. Morphometric counts were made independently by two blinded observers (Z.L. and G.M.) and checked so that no more than a $10 \%$ difference existed between counts from the two observers.

\section{Statistical analysis}

The data for weight and volume were reported as mean $\pm \mathrm{SD}$. For vascular morphometric studies, as well as the cellular proliferation and apoptosis analysis, results were reported as mean \pm SEM for the total number of observations. Statistical comparison between the groups was performed using oneway ANOVA and the Bonferroni multiple comparisons test. The results were considered statistically significant if $P<0.05$.

\section{RESULTS}

\section{Macroscopic appearance of the construct and AVL patency}

At 3 days, the major portion of the new construct tissue was a fibrin clot surrounding the AVL (Fig. 1C) while at subsequent time points a well-vascularized tissue flap surrounded the AVL (Fig. 1D).

Only three chambers demonstrated an occluded AVL when tested surgically (one specimen at 28, 56, and 112 days) and were excluded from the study. Histologically, 13 chambers demonstrated partial occlusion of the AVL by thrombus (24.5\% of all chambers) and another 8 (15.1\% of total) demonstrated complete occlusion. Partial and complete occlusions were evenly spread throughout the groups, with the majority at the vein graft-femoral vein anastomosis. All occlusions became revascularized and the tissue around the occluded vessels appeared healthy, as did all tissue throughout the chamber constructs.

\section{AVL histology}

The artery wall of the AVL maintained a normal muscular artery structure (Fig. 1E), although some medial SMC loss occurred in the first few weeks.

The femoral vein was significantly altered at $7-10$ days, with the appearance of new capillaries within the wall and connecting to the lumen (Fig. 1F). SMC loss occurred in the vein media and large numbers of cells were observed migrating through the vein wall. The endothelial layer was difficult to recognize as much of it was "thickened" or had a piled-up appearance due to a massive influx of cells, many of them inflammatory cells (Fig. $1 F)$.

The vein graft demonstrated loss of ECs and many SMCs at 3 days (Fig. $1 G$ ). At later times endothelium covered the graft luminal surface, while the graft media was largely devoid of SMCs throughout the study period (Fig. 1H). Cells migrating through the graft wall were noted. Confined areas of thin neointimal hyperplasia developed in the vein graft wall near its anastomosis with the artery, from 14 days. 
Tissue weight and volume displacement analysis

The heaviest constructs were observed at 7 $(0.374 \pm 0.100 \mathrm{~g})$ and 10 days $(0.349 \pm 0.068 \mathrm{~g})$ (Fig. $1 I)$. The highest mean volume was observed at 7 days $(0.330 \pm 0.102 \mathrm{ml})$ and 10 days $(0.316 \pm 0.069 \mathrm{ml})$ (Fig. $1 \mathrm{~J})$. After day 10, the weight and volume decreased slightly, then stabilized after day 14.

\section{Characterization of tissue growth and identification of cell types}

At 3 days a large fibrin clot had exuded from the AVL and filled most of the chamber (Fig. 2A, B). No collagen was observed around the AVL. Inflammatory cells (neutrophils and ED-1-positive macrophages) were seen migrating through the fibrin. Spindle-shaped cells, the majority being $\alpha$-SMA-positive myofibroblasts, were also observed in the fibrin around the AVL vein (Fig. 3B). A few larger spindle-shaped cells were VEGFR-2-positive (Fig. $\mathbf{4 B}$, also observed at 7 days; Fig. $4 D)$. Thy-1- and c-kit-positive cells were rarely seen in the fibrin matrix.

By day 7 (Fig. $2 C, D$ ) the fibrin matrix around the AVL was partially replaced by newly formed vascularized connective tissue. Tissue development varied, but was always more extensive adjacent to the femoral vein of the AVL. Masson's trichrome staining demonstrated newly synthesized collagen replacing the fibrin. The maturing vascularized connective tissue zone was deposited directly adjacent to the AVL, while a hemorrhagic proliferative zone lay sandwiched between the
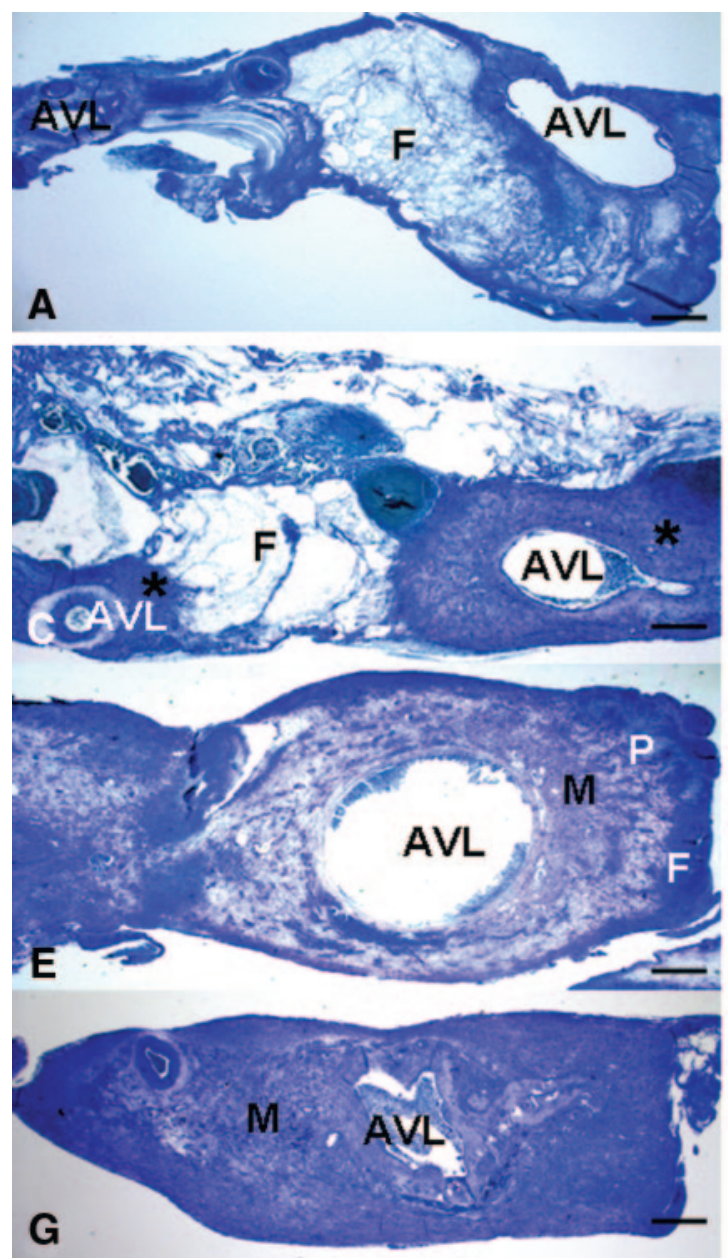

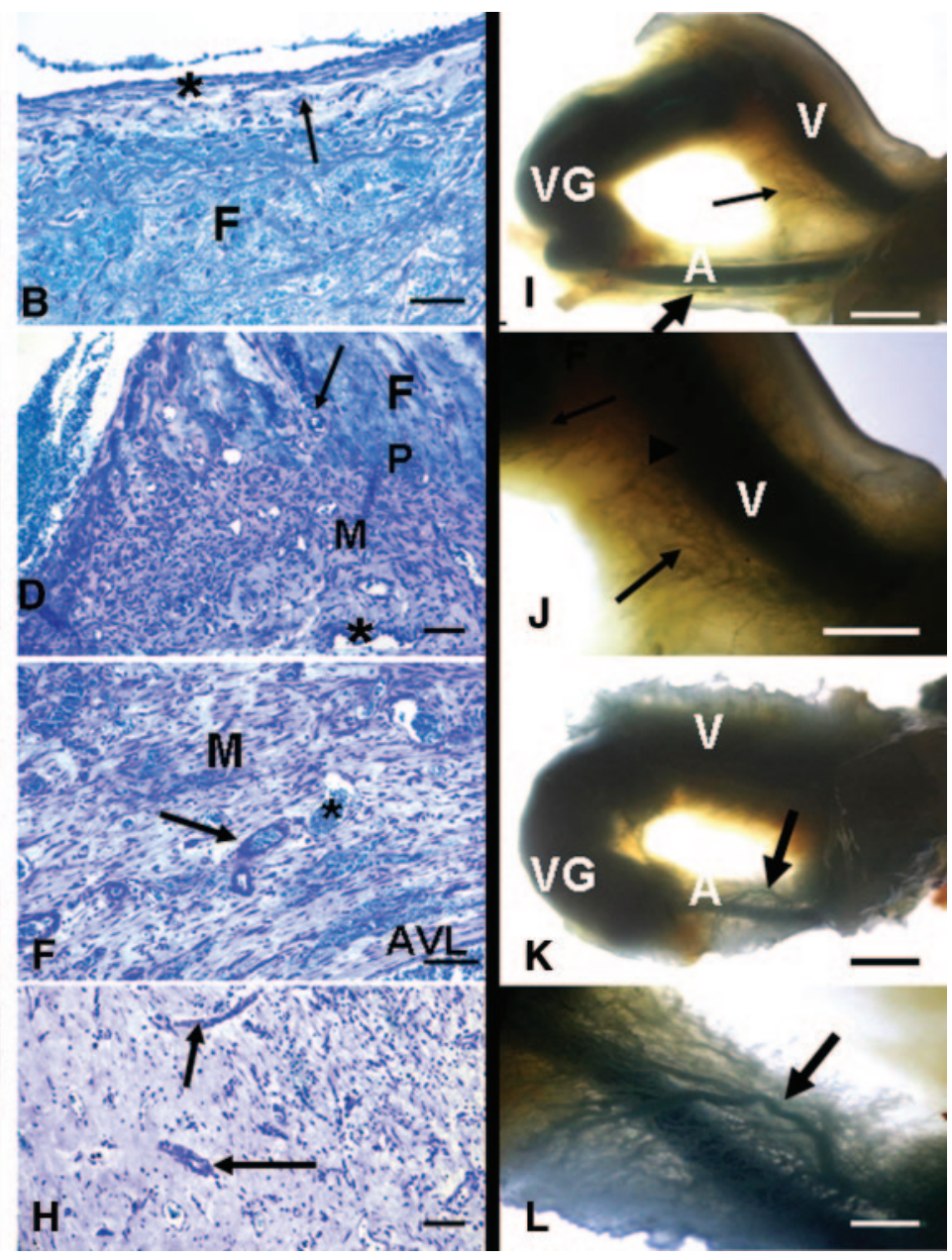

Figure 2. a-h. Toluidine blue staining of vertical sections through AVL constructs. $A, B$ ) At 3 days, the AVL surrounded by fibrin matrix (F). B) Inflammatory and mesenchymal cells (arrow) begin to migrate into the fibrin. (asterisk: AVL wall). C) At 7 days, two cross sections through the AVL, now surrounded by a cuff of new connective tissue (asterisks) and fibrin (F). D) At 7 days, the AVL (asterisk) surrounded by maturing connective tissue $(\mathrm{M})$. Further from the AVL is the proliferative zone (P), including new capillaries (arrow) migrating into the fibrin $(\mathrm{F}) . E$ ) At 14 days, the AVL is surrounded by a wide cuff of mature vascularized connective tissue $(\mathrm{M})$. The proliferative zone $(\mathrm{P})$ and fibrin matrix $(\mathrm{F})$ are reduced in width. F) Mature connective tissue (M) at 14 days: arrow indicates arteriole; asterisk indicates venule. $G$ ) At 28 days, the AVL is covered by mature vascularized connective tissue $(\mathrm{M})$. No fibrin is evident. $H$ ) Mature tissue: arrows, blood vessels. Scale bars: $A, C, E, G)=500 \mu \mathrm{m} ; B, D, G$, $H)=50 \mu \mathrm{m} . I-L)$ Resin casts of the AVL at day $10(I, J)$ and day $14(K, L)$. No capillaries or arterioles sprout from the vein graft (VG) $(I, K)$. Capillaries sprout (arrows) from the femoral vein (V) at 10 days $(I, J)$. Occasional arterioles (thick arrows) branch from the femoral artery (A) at day $10(I)$ but were far more numerous at day $14(K, L)$. Scale bars, $I-L=2 \mathrm{~mm}$. 

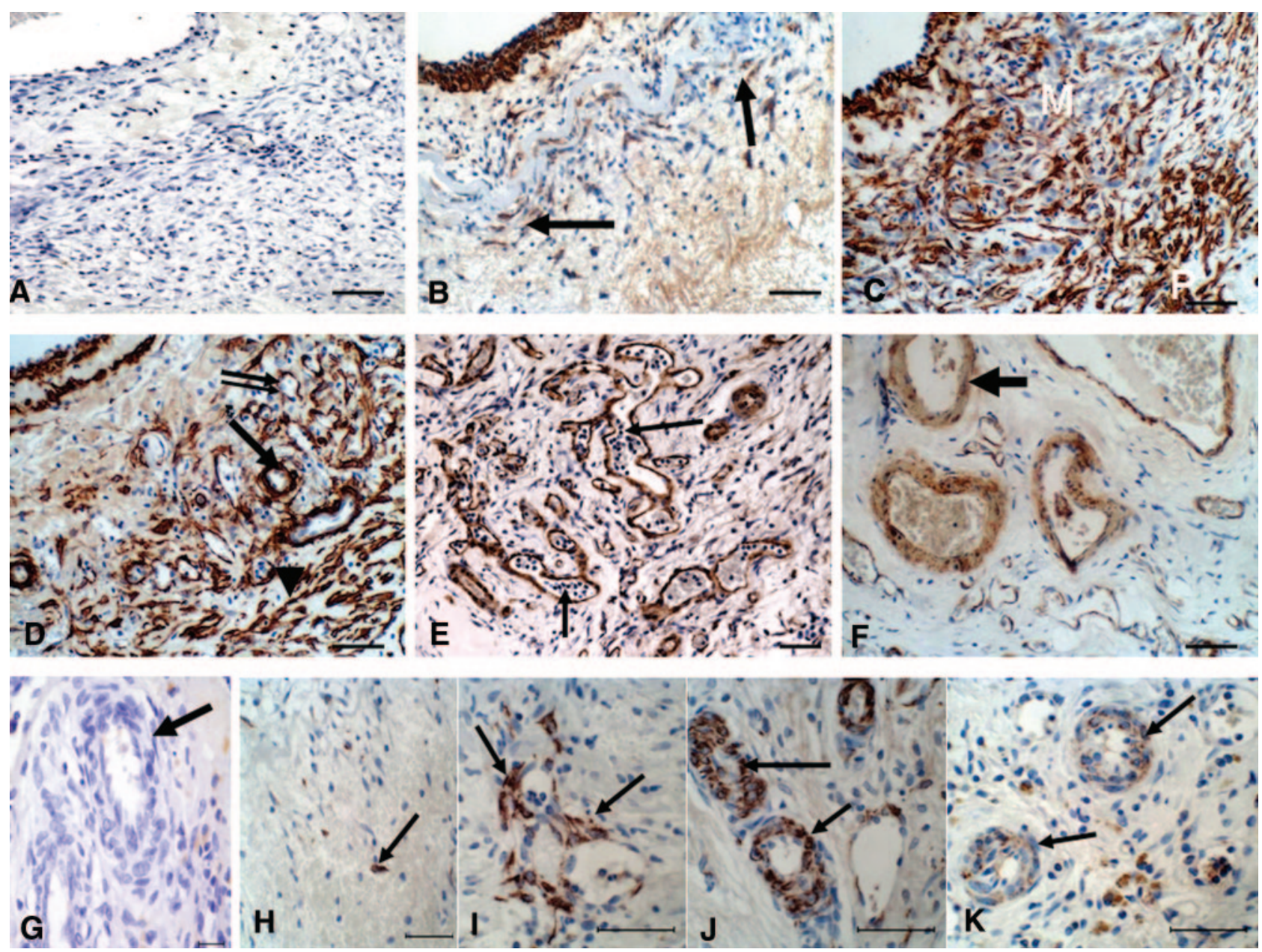

Figure 3. $\alpha$-SMC and desmin labeling in AVL constructs. A) Negative control tissue from a 10 day construct. No $\alpha$-SMA labeling is evident. Scale bar $=50 \mu \mathrm{m}$. B) At 3 days, $\alpha$-SMA-positive cells (arrows) in the fibrin surrounding the AVL. Scale bar $=50 \mu \mathrm{m}$. C) At 7 days, numerous $\alpha$-SMA-positive cells in the proliferative zone $(\mathrm{P})$ and mature connective tissue zone $(\mathrm{M})$. Scale bar $=$ $50 \mu \mathrm{m}$. D) At 10 days, $\alpha$-SMA-positive cells in arteriole walls (thick arrow), surrounding capillaries (double arrow), and as individual cells (arrowhead). Scale bar $=50 \mu \mathrm{m} . E$ ) At 21 days, venules (arrows) labeled with $\alpha$-SMA. Scale bar $=50 \mu \mathrm{m}$. F) At 112 days there is a reduction in $\alpha$-SMA labeling intensity in arterioles (arrow) and interstitium. Scale bar $=50 \mu \mathrm{m}$. $G$ ) No desmin labeling in an arteriole wall (arrow) in negative control tissue from a 10 day AVL construct. Scale bar $=20 \mu \mathrm{m}$. $H$ ) At 7 days, isolated individual cells (arrow) and $I$ ) medial SMCs in small blood vessels (arrow) labeled with desmin. Scale bar: $H$ ) $=100 \mu \mathrm{m}$; $I)=50 \mu \mathrm{m} . J$ ) At 10 days, arteriole wall SMCs (arrows) labeling with desmin. Scale bar $=50 \mu \mathrm{m}$. K) At 21 days, reduction in desmin labeling intensity in arteriole walls (arrows). Scale bar $=50 \mu \mathrm{m}$.

new connective tissue and the remaining fibrin matrix (Fig. 2D). The immature, leaky capillaries of the proliferative zone, which frequently demonstrated a discontinuous endothelial lining, allowed blood to leak into the surrounding fibrin, giving this zone a hemorrhagic appearance that persisted to 28 days. Numerous inflammatory cells, $\alpha$-SMA-positive (Fig. 3C) and desminpositive cells (Fig. $3 H$ ) in the interstitium, and VEGFR2-positive capillaries (Fig. 4C) were observed in the proliferative zone. Consistent with hemorrhage in the construct was the accumulation of hemosiderin-filled macrophages from 14 days.

The first arterioles were generally observed at 7-10 days (Fig. 3D) . $\alpha$-SMA-positive and desmin-positive cells (Fig. $3 D, I, J$ ) were observed in arteriole and capillary walls. Definitive venules appeared at 14-21 days (Fig. $3 E$ ). Arterioles and venules persisted to 112 days (Fig. $3 F, K)$.
As the fibrin matrix was gradually replaced by the new microcirculation and connective tissue (Fig. 2E$H$ ), cell populations throughout the construct also changed. Between 21 and 112 days, the numbers of desmin- and $\alpha$-SMA-positive cells was markedly reduced in the interstitial connective tissue, and reduced staining intensity was noted in blood vessel walls (Fig. $3 F, K$ ). VEGFR-2 staining was maximal at 10 days (Fig. $4 E$ ) in new vessel sprouts and largely confined to the proliferative zone. Weak VEGFR-2 labeling was observed at 14 days and was undetectable from 21 days onward (Fig. $4 F)$. These changes occurred concurrently with a general reduction in cellularity in the connective tissue.

\section{Vascular casting}

Three day AVL constructs demonstrated no capillary sprouting when examined under a dissecting micro- 

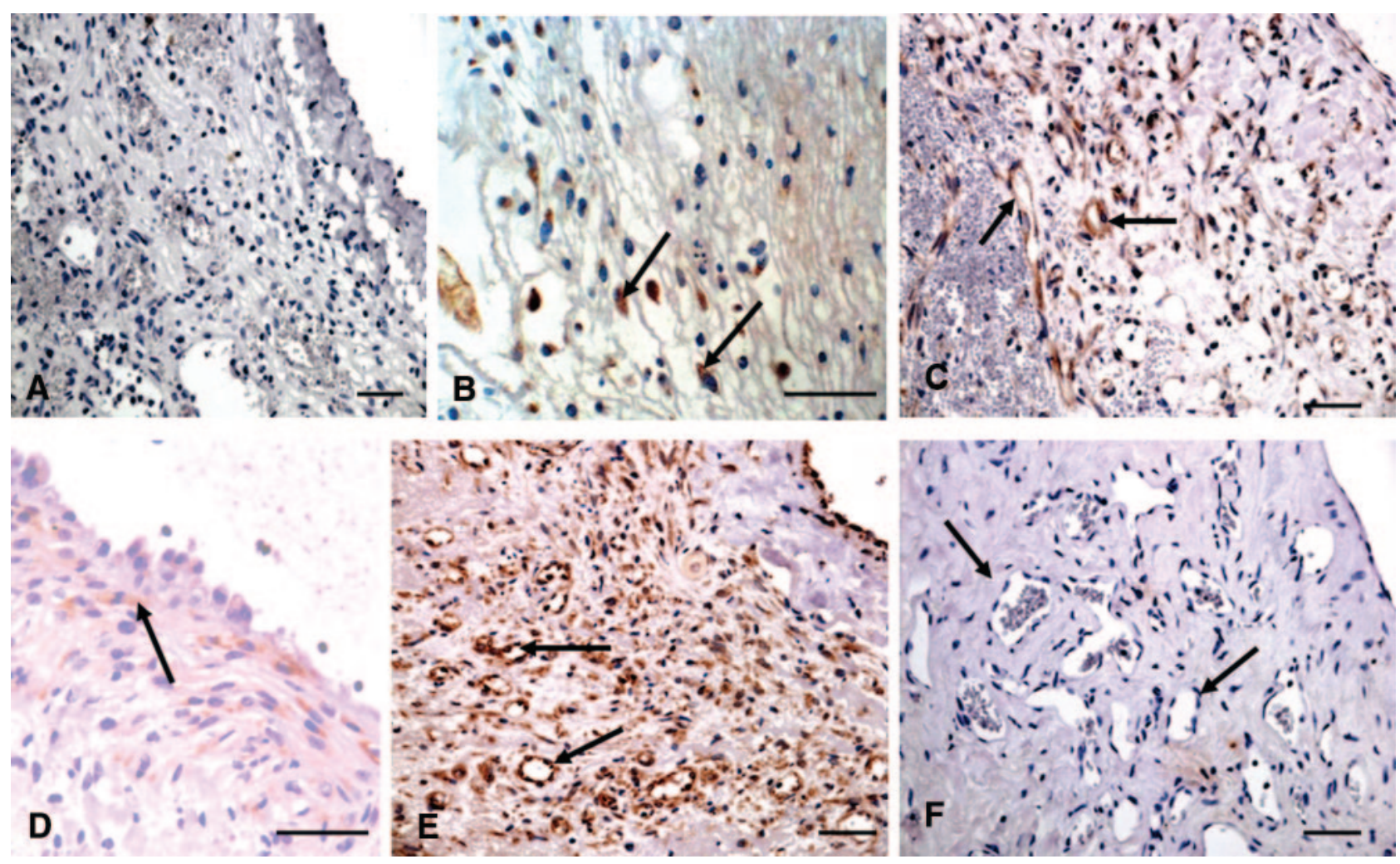

Figure 4. VEGFR-2 labeling. A) VEGFR-2 labeling is absent in negative control tissue in a 7 day construct. Scale bar $=50 \mu \mathrm{m}$. $B$ ) At 3 days, isolated VEGFR-2-positive cells (arrows) in the fibrin matrix surround the AVL femoral vein. Scale bar $=50 \mu \mathrm{m}$. C) At 7 days, VEGFR-2 labeling in capillary endothelium (arrows) in the proliferative zone. Scale bar $=50 \mu \mathrm{m}$. $D$ ) Femoral vein at 7 days, including large VEGFR-2-positive cells (arrow) in the vein wall outside the endothelial layer. The VEGFR-2-positive cell indicated is dividing. Scale bar $=50 \mu \mathrm{m}$. E) At 10 days, VEGFR-2 labeling in capillaries (arrows). Scale bar $=50 \mu \mathrm{m} . F$ ) At 28 days, blood vessels (arrows) no longer label with VEGFR-2. Scale bar $=50 \mu \mathrm{m}$.

scope. Capillary sprouts were seen extending from the femoral vein at 7 days, with profuse sprouting from the vein at day 10 (Fig. 2I, J). At day 10 a few arteriolar-like sprouts from the recipient artery were noted (Fig. 2I). More extensive sprouting was observed at 14 days from both the femoral artery (Fig. $2 K, L$ ) and vein, but not from the vein graft. Blood vessel sprouts were not evident from the vein graft at any time examined (Fig. $2 I, K)$. However, both the artery- and vein-derived sprouts grew in the direction of the vein graft and coursed along its abluminal surface.

\section{TEM identification of early blood vessel growth}

Several morphologies of new capillary formation were observed in 7 day AVL constructs. A distinctive feature were numerous large elongated or "tear-drop"-shaped cells having an immature mesenchymal appearance, presumed to be endothelial precursors. These cells had a large open oval nucleus with a narrow rim of chromatin clumping and cytoplasm filled with granular endoplasmic reticulum. These large cells often appeared in groups frequently aligned parallel to one another (Fig. 5A). The majority did not appear to make cell-cell contact, although occasional contact and slight overlapping was observed. Individual cells containing extremely dilated endoplasmic reticulum, giving the cell a vacuolated appearance (Fig. 5B) - possibly indicating lumen formation-were also present. In addition, definitive solid capillary sprouts were seen (Fig. $5 C$ ). Slightly later stages of sprout development (Fig. $5 D$ ), where the shape and alignment of two opposite ECs appeared complementary (suggesting that the two might have formed a solid cord and then separated to form a lumen) were evident. In capillary sprouts the capillary endothelial cell was thick (Fig. $5 \mathrm{C}$ ), containing much granular endoplasmic reticulum and many free ribosomes. The nuclear appearance was becoming more elongated and irregular in outline, with denser and more prominent peripheral clumping.

Pericytes were observed on the abluminal surface of the capillary (Fig. 5D). Their morphology was not dissimilar to that of the endothelium; however, a conspicuous feature were numerous free ribosomes within their cytoplasm. Before their alignment to the abluminal surface of a capillary, it was impossible to morphologically distinguish individual pericytes from ECs.

\section{Hypoxia studies}

Positive control liver tissue in animals receiving hypoxyprobe-1 demonstrated labeling in many liver hepatocytes (Fig. 6A). Negative control tissue did not demonstrate labeling (Fig. 6B, C). Hypoxic inflammatory 


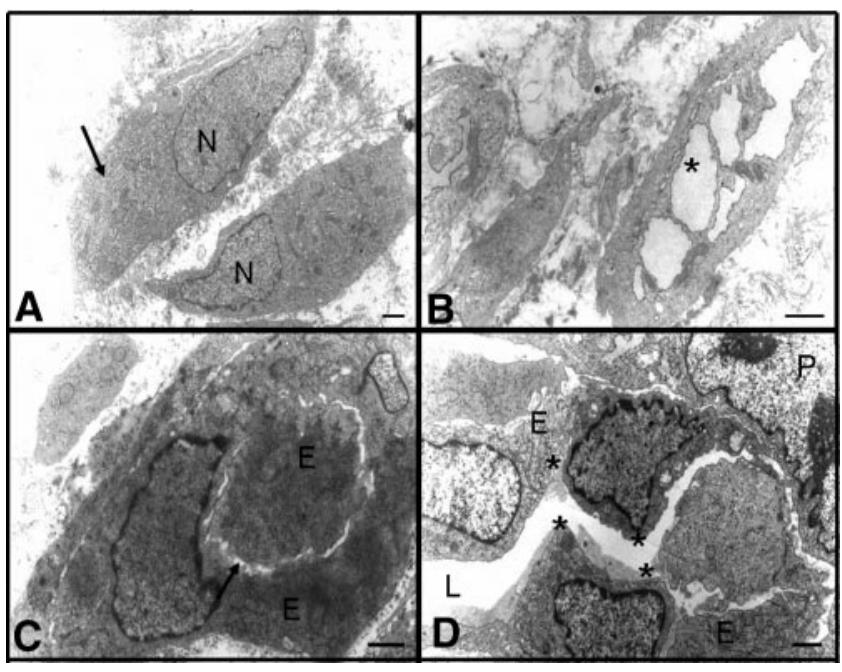

Figure 5. TEM of new blood vessel formation in 7 day AVL constructs. A) Two large tear drop-shaped mesenchymal cells containing an undifferentiated nucleus (N) and large amounts of endoplasmic reticulum (arrow). Scale bar $=1$ $\mu \mathrm{m} . B)$ Mesenchymal cells containing extremely dilated vacuoles (asterisk), possibly indicative of lumen formation. Scale bar $=1 \mu \mathrm{m} . C$ ) A solid capillary sprout with a slight widening of the intercellular space (arrow) indicating early lumen formation. E: endothelial cells. Scale bar $=1 \mu \mathrm{m}$. D) A later stage of sprout development with a lumen (L) apparent between endothelial cells (E). The opposite sides of the endothelial lining appear to fit together (asterisks), suggesting they were previously interlocked as a solid sprout. P: pericyte. Scale bar $=1 \mu \mathrm{m}$. cells (predominantly neutrophils and monocytes) and myofibroblasts were observed throughout the fibrin matrix at 3 days (Fig. 6D). Hypoxyprobe-1 labeling was most intense and widespread at 7 days (Fig. 6E), occurring within capillary endothelium and interstitial cells throughout the cuff of new connective tissue formed around the AVL. Labeling was most intense at the front of the migrating proliferative zone whereas mature tissue adjacent to the AVL did not label (Fig. $6 E, F)$, indicating adequate oxygen perfusion to this new tissue. From 14 days, as the proliferative zone gradually disappeared, hyproxyprobe-1 labeling diminished (Fig. 6G) and was absent from 28 days onward.

\section{Morphometric determination of connective tissue components and vascular volume density}

At 3 days the percent volume of fibrin was 75.18 ( \pm 4.0$)$ $\%$, being significantly higher than all subsequent time points (Fig. 7A). Fibrin percent volume rapidly declined to $22 \%( \pm 2.38 \%)$ at 14 days and was almost undetectable at 112 days $(0.19 \pm 0.19 \%)$. The connective tissue component showed the opposite trend, being $<10 \%(6.14 \pm 2.91 \%)$ at 3 days, but increased significantly $(P<0.001)$ to $57.43 \%( \pm 3.57 \%)$ at 14 days. This level was maintained over the subsequent time frame studied (Fig. 7A).

Blood vessel percent volume was observed to increase from $<1 \%$ at 3 days to $>10 \%$ at 10 days, and remained
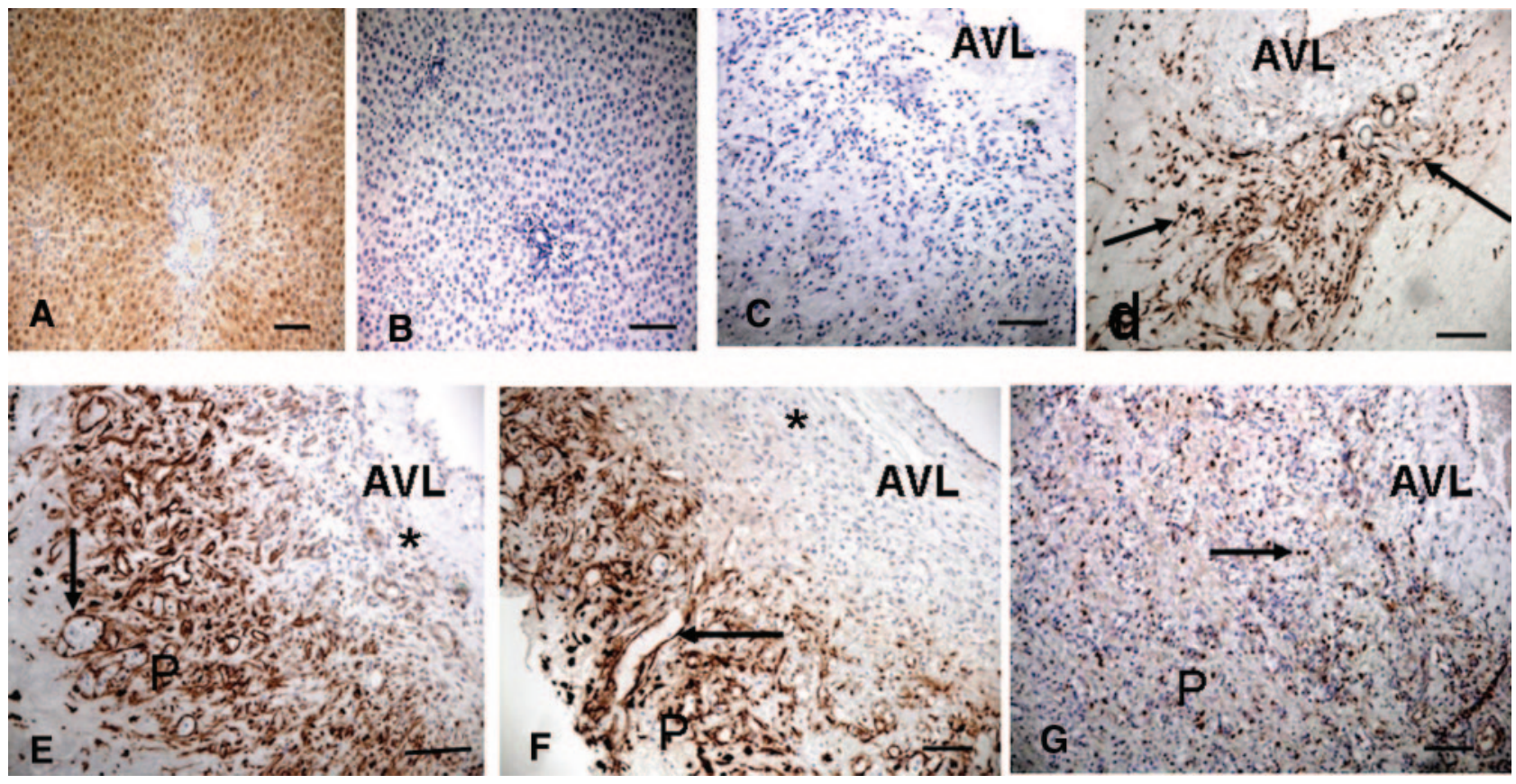

Figure 6. Demonstration of hypoxia in AVL constructs with hypoxyprobe-1 labeling. A) Positive control liver hepatocytes. Scale bar $=100 \mu \mathrm{m} . B$ ) Absence of hypoxyprobe-1 labeling in negative control liver tissue from an animal that did not receive hypoxyprobe-1. Scale bar $=100 \mu \mathrm{m}$. C) Negative control tissue (without application of primary antibody) from a 7 day construct demonstrating no labeling. Scale bar $=100 \mu \mathrm{m}$. D) At 3 days, individual cells (arrows) positively label for hypoxyprobe-1 in the fibrin matrix adjacent to the AVL. Scale bar $=100 \mu \mathrm{m}$. E) At 7 days; $F$ ) at 10 days, positive labeling in a cuff of tissue corresponding to the proliferative zone $(\mathrm{P})$. New capillaries (arrows) and interstitial cells label. The mature connective tissue adjacent to the AVL does not label (asterisks). Scale bars $=100 \mu \mathrm{m}$. G) At 14 days the AVL and proliferative zone (P) do not label, but individual macrophages still label (arrow). Scale bar $=100 \mu \mathrm{m}$. 


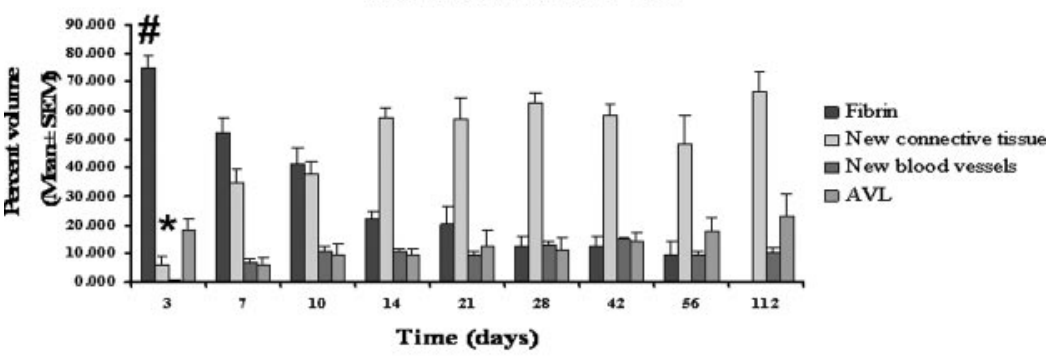

B

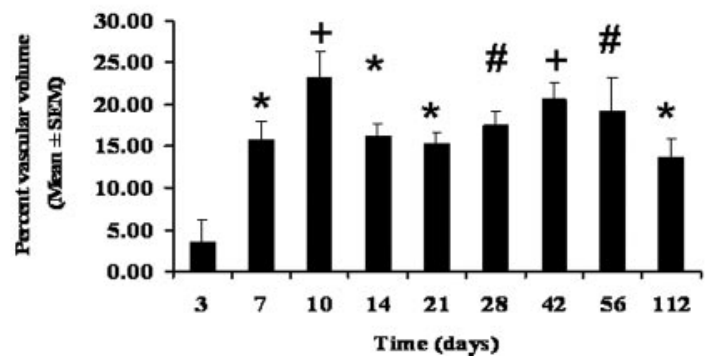

Figure 7. Percent volume of construct tissue components. A) Percent volume of construct tissues: fibrin, connective tissue, blood vessels, and AVL from 3 to 112 days. "Percent volume of fibrin at 3 days is significantly higher than at all subsequent time points ( 7 days, $P<0.05 ; 10,14$, $21,28,42,56$, and 112 days, $P<0.001)$. *Percent volume of connective tissue at 3 days is significantly less than that at all subsequent time points ( 7 days, $P<0.05$; 10 days, $P<0.01 ; 14$, 21, 28, 42, 56, and 112 days, $P<0.001)$. B) Percent vascular volume of new blood vessels in connective tissue from 3 to 112 days. ${ }^{* \#,+}$ Percent vascular volume was significantly higher at 7-112 days compared with 3 day AVL constructs (*7, 14, 21,112 days, $P<0.05$; ${ }^{*} 28,56$ days, $P<0.01 ;{ }^{+} 10,42$ days, $\left.P<0.001\right)$. at approximately this value for up to 112 days. It was considered more appropriate to determine percent vascular volume in relation to the new connective tissue produced in the construct (see below) rather than the entire construct, as the latter includes clearly avascular zones such as the fibrin matrix.

Vascular volume density was determined as a percentage of connective tissue in AVL constructs over time (Fig. $7 B$ ). Vascularization of the chamber construct starts between 3 and 7 days, and increased significantly to peak at 10 days $(23.20 \pm 3.14 \%, P<0.001$, day 3 vs. day 10$)$. Vascular volume percent declined slightly after 10 days but was maintained at 112 days at $13.73 \%$ ( $\pm 2.14 \%)$.

\section{Proliferation and apoptotic cell studies}

At 3 days, a few proliferating cells were observed in the fibrin matrix but not in the EC or SMCs of the AVL. From 7 days onward, Ki67-positive cells included predominantly pericytes, ECs (Fig. 8B), and myofibroblasts in the new connective tissue and occasionally in the femoral vein and artery wall. A significantly increased and maximal proliferative cell number was observed at 7 days $\left(114.6 \pm 17.3\right.$ cells $/ \mathrm{mm}^{2}, P<0.001,7$ days $v s .3$ days) (Fig. 8C).

The first apoptotic cells in the chamber were spindleshaped cells seen at the periphery of the migrating

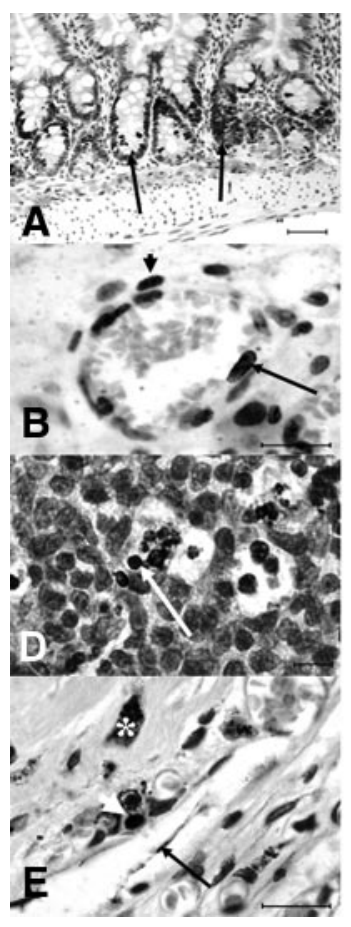

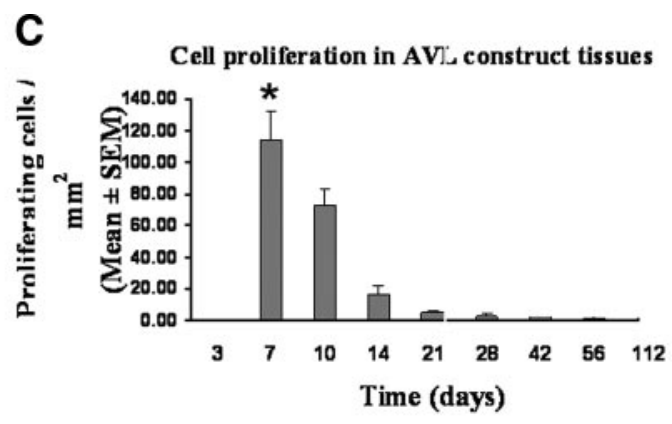

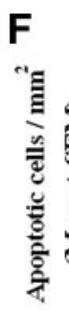

Figure 8. Cell proliferation and apoptosis in AVL constructs. A) Positive control tissue demonstrating Ki67 labeling in the small intestinal crypts (arrows). Scale bar $=50 \mu \mathrm{m}$. B) At 7 days, Ki67 labeling in the endothelium (arrow) and in a pericyte (arrowhead) wrapped around the endothelial abluminal surface. Scale bar $=2$ $\mu \mathrm{m}$. C) Cell proliferation (proliferating cells/ $\mathrm{mm}^{2}$ ) in AVL constructs from 3 to 112 days. *Cell proliferation was significantly higher at 7 days compared with $3(P<0.001), 10(P<0.01)$, and $14,21,28,42,56$, and 112 day groups $(P<0.001)$. D) Positive control: labeling of apoptotic cells in rat lymph node (arrow). Scale bar $=10 \mu \mathrm{m}$. E) Detachment of an apoptotic EC (arrow) from the underlying capillary basement membrane in a 112 day construct. Apoptotic cells are present outside the blood vessel and include pericytes (white arrowhead) and macrophages (white asterisk). Scale bar $=2$ $\mu \mathrm{m} . \mathrm{F}$ ) Cell apoptosis (apoptotic cells $/ \mathrm{mm}^{2}$ ) in AVL constructs from 3 to 112 days. Macrophages containing apoptotic bodies were excluded from the counts. The number of apoptotic cells $/ \mathrm{mm}^{2}$ was significantly higher at 56 and 112 days compared with the $3,7,10,14$ $(P<0.001)$ and the 21 day group $(P<0.01)$. 
tissue at 7 days. The first apoptotic blood vessels were observed at 21 days, although these were isolated events. At later times apoptotic cells included fibroblasts, macrophages, occasional pericytes, and capillary ECs (Fig. 8E). Capillary apoptosis was accompanied by arteriolar apoptosis with SMCs/pericytes labeling with TUNEL. The number of apoptotic cells $/ \mathrm{mm}^{2}$ increased over time and was greatest at 112 days (31.5 \pm 3.4 cells $/ \mathrm{mm}^{2}, P<0.001,112$ days vs. $3,7,10$, and 14 days (Fig. $8 F$ ).

\section{DISCUSSION}

Vascularization in experimental tissue engineering had not been previously examined in detail. Little attempt has been made to characterize extrinsic vascular ingrowth and no medium or long-term studies have been published that examine vascular remodeling in engineered constructs. In the study reported here, the development, maturation, and remodeling of vasculature and connective tissue in an intrinsically vascularized (28) tissue engineering model, based on growth of tissue from a macrovascular arteriovenous loop inserted into a space and protected by chamber walls, were investigated for up to 112 days.

The spontaneous vascular growth in the AVL construct was preceded by fibrin exudation from the AVL, which filled the empty chamber. Fibrin has been acknowledged as being proangiogenic (29); in this model it also acts as a natural provisional matrix for development of a new microcirculatory network.

Intense early angiogenesis from the AVL accompanied by the migration of myofibroblasts into the fibrin matrix was observed. At 10 days the percent vascular volume density of new tissue was $23.20 \pm 3.14 \%$. This is a surprisingly high level compared with angiogenesis observed during primary intention incisional skin wound healing, where the maximal percent vascular volume at 7 days was $15.83 \pm 1.10 \%$ (23). What stimulates AVL angiogenesis is unclear; however, the identification of hypoxyprobe-1 labeling at 3 days in the absence of any angiogenic vessel formation off the AVL and before maximal angiogenesis at 10 days suggests that hypoxia may be a major driving factor (30). The presence of a proangiogenic fibrin matrix (29), mechanoreceptive forces acting when the AVL is placed in a large empty chamber space $(31,32)$, and shear stress (33) within the AVL (34) are likely to positively influence the angiogenic response from the AVL.

The highest number of proliferating cells, which included endothelial, pericyte, and myofibroblast populations in the construct, was observed at 7 days in the presence of a hypoxic environment, suggesting that hypoxia is a stimulant of cellular and vessel proliferation in the AVL construct. The peak of proliferation preceded the peak of vascular volume, indicating that the new vessels could develop in response to the increased cellular population present in the construct matrix.

Both histological and vascular cast observations suggest that capillaries first appear around the vein portion of the AVL between 3 and 7 days, whereas arterioles appear around the artery portion of the AVL between 7 and 10 days (Fig. 9). Vascular casts also demonstrated no sprouting from the vein graft segment of the loop in the first 14 days, when overall vascular growth was maximal. A clear directional pull of both venous and arterial sprouts along the axis of the vein graft (observed for up to 14 days) may be related to a more hypoxic environment around the graft that does not generate any new vessels. Together with the previous findings that blind ending ligated arteriovenous vascular pedicles without an intervening vein graft resulted in sprouting of a significant vascular plexus in vivo (34),
Figure 9. Graphic summarizing the events in the AVL chamber resulting in the production of a complex microcirculatory network.

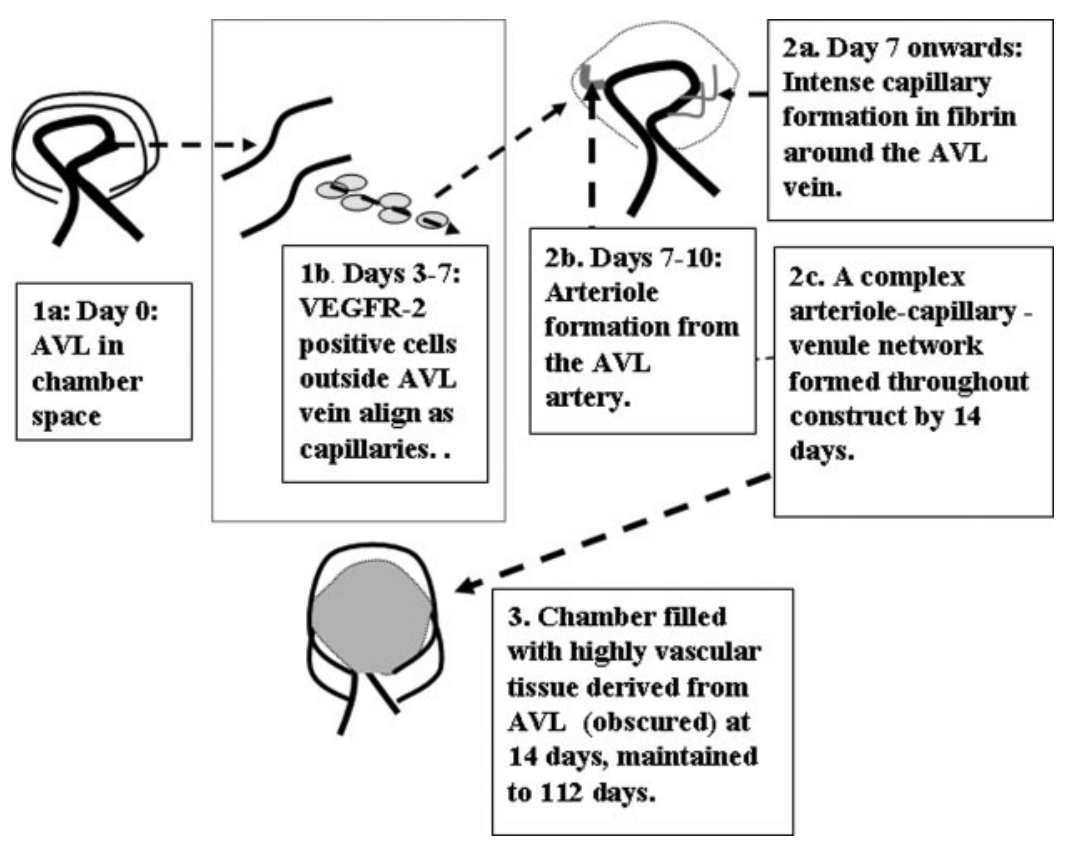


these results suggest that the vein graft is not necessary for the formation of a microcirculatory plexus from the AVL, and indicate that reduced donor site scarring and quicker operative times could be achieved by using a ligated pedicle or "off the shelf" synthetic or bioengineered vascular grafts.

Light microscopic, immunohistochemical, and TEM observations suggest that undifferentiated cells in and adjacent to the recipient vein wall migrate into the fibrin matrix in aligned groupings of cells often appearing to be moving parallel to one another (Fig. 9). The close proximity of these cells to one another suggests that they eventually achieve cell-to-cell contact, forming a sprout. This method of capillary formation has been described (35). In addition, solid endothelial sprouts without a lumen or with a narrow lumen were observed, suggesting lumen formation by separation of individual ECs from one another (35).

In addition to the capillary network, the first arterioles were initially seen around the recipient artery relatively early (between 7 and 10 days), as observed both in vascular casts and histologically. Venules were apparent at 14-21 days. The AVL construct therefore forms an extensive arteriole-capillary-venule network, peaking in percent vascular volume at 10 days and continuing to mature thereafter. This vascular network, though undergoing remodeling, remains intact at 112 days.

The presence of apoptotic cells within the new tissue rose gradually from 14 days to reach a maximal num$\mathrm{ber} / \mathrm{mm}^{2}$ at 112 days, suggesting that the actual peak in apoptosis could be beyond this time point. When compared with the blood vessel remodeling in primary intention incisional skin wounds (23), which peaks at 21 days, remodeling in the AVL construct occurs much later. Remodeling via apoptosis was evident in capillary ECs and in pericytes and SMCs/pericytes around arterioles, but this remodeling did not cause a significant loss of microcirculation as measured by percent vascular volume. The increase in cell apoptosis from 14 days occurred in the absence of detectable hypoxia, thus excluding the possibility that hypoxia could activate cellular apoptosis (36) in this model. Whether microcirculatory remodeling occurs in response to changes in growth factor concentration, remodeling of the ECM, loss of interstitial connective tissue cells $(37,38)$, and/or is a consequence of lack of functional demand on the formed vascular network remains to be determined.

The AVL construct presents a temporal window for cellular manipulation between the angiogenic growth phase and commencement of remodeling of the formed tissue. Cell proliferation and angiogenesis are maximal at 7 and 10 days, respectively, suggesting that at this time the AVL construct is most suitable for tissue engineering-directed manipulation. In particular, this time presents an ideal opportunity for the seeding of stem or progenitor cells that could proliferate, differentiate, and expand in the chamber space to develop specific tissue types while simultaneously being nourished by the developing microcirculation.

Placement of a macrovascular AVL in an empty polycarbonate chamber leads to the spontaneous generation of a microcirculatory network. It can be concluded that:

1) Angiogenic and connective tissue growth in the AVL chamber model occurs under hypoxic conditions, whereas the remodeling phase does not occur under hypoxic conditions. 2) A natural transient ECM, a fibrin exudate, supports early radial blood vessel growth from the AVL. 3) Adult tissue growth normally is stimulated by injury, functional demand, or endocrine stimulus. In the rigid noncollapsible chamber, tissue growth is amplified by the presence of a large, permanent, defined tissue space that protects the fibrin matrix, which under normal conditions would be dissipated into adjacent tissues. Within this protected space, new tissues and vasculature can expand. The provision of space for growth in this model appears highly significant and represents a new paradigm of vascularized tissue growth. 4) A temporal window exists between 7 and 10 days appropriate for seeding exogenous stem or progenitor cells to achieve development of specific tissues in the presence of concurrent active vascularization. 5) Vascular and cellular remodeling of the construct tissue through apoptosis commences $\sim 14-21$ days and reaches a peak at 112 days. Analysis of the tissue weight, volume, percent vascular volume, and general histological assessment indicate that this remodeling is not detrimental to the viability of the tissue construct.

The AVL chamber model with its intense early vascularization has enormous potential to allow manipulation of the chamber constituents so as to direct growth to specific tissue or organ end points. The model therefore has direct clinical application in growing new tissues and organs for reconstructive surgery, organ, and tissue replacement.

This study was supported by the St. Vincent's Hospital Melbourne Research Grant 2003/48 and Microsurgery Foundation Grant awarded to Z.L. Z.L. is also a recipient of Melbourne Research Scholarship. We gratefully acknowledge the assistance of Ms. Ana Friedhuber for her help with TEM, and Mr. Jason Palmer, Dr. James Thomas, and the staff of the Experimental and Medical Surgical Unit, St. Vincent's Hospital, Melbourne.

\section{REFERENCES}

1. ANZOD Registry Report 2004. Excell, L., Russ G. R., and Wride, P., eds (2004) Australia and New Zealand Organ Donation Registry. Adelaide, South Australia.

2. Paige, K. T., and Vacanti, C. A. (1995) Engineering new tissue: formation of neocartilage. Tissue Eng. 1, 97-106

3. Auger, F. A., Berthod, F., Moulin, V., Pouliot, R., and Germain, L. (2004) Tissue-engineered skin substitutes: from in vitro constructs to in vivo applications. Biotechnol. Appl. Biochem. 39, 263-275

4. Park, K. D., Kwon, I. K., and Kim, Y. H. (2000) Tissue engineering of urinary organs. Yonsei Med. J. 41, 780-788 
5. Ratcliffe, A. (2000) Tissue engineering of vascular grafts. Matrix Biol. 19, 353-357

6. Mian, R., Morrison, W. A., Hurley, J. V., Penington, A. J., Romeo, R., Tanaka, Y., and Knight, K. R. (2000) Formation of new tissue from an arteriovenous loop in the absence of added extracellular matrix. Tissue Eng. 6, 595-603

7. Carmeliet, P. (2000) Mechanisms of angiogenesis and arteriogenesis. Nat. Med. 6, 389-395

8. Crosby, J. R., Kaminski, W. E., Schatteman, G., and Martin, P. J. (2000) Endothelial cells of hematopoietic origin make a significant contribution to adult blood vessel formulation. Circ. Res. 87, 728-730

9. Chan-Ling, T., Baxter, L., Fatal, A., Segesta, N., Caballero, S., Rosinova, E., and Grant, M. B. (2006) Hematopoietic stem cells provide repair functions after laser-induced Bruch's membrane rupture model of choroidal neovascularization. Am. J. Pathol. 168, 1031-1044

10. Black, A. F., Berthod, F., L'Heureux, N., Germain, L., and Auger, F. A. (1998) In vitro reconstruction of a human capillarylike network in a tissue-engineered skin equivalent. FASEB J. 12, $1331-1340$

11. Frerich, B., Lindemann, N., Kurtz-Hoffmann, J., and Oertel, K. (2001) In vitro model of a vascular stroma for the engineering of vascularized tissues. Int. J. Oral Maxillofac. Surg. 30, 414-420

12. Levenberg, S., Rouwkema, J., Macdonald, M., Garfein, E. S., Kohane, D. S., Darland, D. C., Marini, R., van Blitterswijk, C. A., Mulligan, R. C., D'Amore, P. A., and Langer, R. (2005) Engineering vascularized skeletal muscle tissue. Nat. Biotechnol. 23, $879-884$

13. McIntire, L. V. (2002) Vascular assembly in engineered and natural tissues. Ann. N. Y. Acad. Sci. 961, 246-248

14. Elcin, Y. M., Dixit, V., and Gitnick, G. (2001) Extensive in vivo angiogenesis following controlled release of human vascular endothelial cell growth factor: implications for tissue engineering and wound healing. Artif. Organs. 25, 558-565

15. Rinsch, C., Quinodoz, P., Pittet, B., Alizadeh, N., Baetens, D., Montandon, D., Aebischer, P., and Pepper, M. S. (2001) Delivery of FGF-2 but not VEGF by encapsulated genetically engineered myoblasts improves survival and vascularization in a model of acute skin flap ischemia. Gene Ther. 8, 523-533

16. Tabata, Y., Miyao, M., Inamoto, T., Ishii, T., Hirano, Y., Yamaoki, Y., and Ikada, Y. (2000) De novo formation of adipose tissue by controlled release of basic fibroblast growth factor. Tissue Eng. 6, 279-289

17. Lu, Y., Shansky, J., Del Tatto, M., Ferland, P., Wang, X., and Vandenburgh, H. (2001) Recombinant vascular endothelial growth factor secreted from tissue-engineered bioartificial muscle promotes localised angiogenesis. Circulation 104, 594-599

18. Lee, K. Y., Peters, M. C., and Mooney, D. J. (2003) Comparison of vascular endothelial growth factor and basic fibroblast growth factor on angiogenesis in SCID mice. J. Control Release 87, 49-56

19. Koike, N., Fukumura, D., Gralla, O., Au, P., Schechner, J. S., and Jain, R. K. (2004) Tissue engineering: creation of long-lasting blood vessels. Nature 428, 138-139

20. Scherle, W. (1970) A simple method for volumetry of organs in quantitative stereology. Mikroskopie 26, 57-60

21. Karnovsky, M. J. (1965) A formaldehyde-glutaraldehyde fixative of high osmolarity for use in electron microscopy. J. Cell Biol. 27, $137 \mathrm{~A}$

22. Hossler, F. E., and Douglas, J. E. (2001) Vascular corrosion casting: Review of advantages and limitations in the application of some simple quantitative method. Microsc. Microanal. 7, 253-264
23. Lokmic, Z., Darby, I. A., Thompson, E. W., and Mitchell, G. M. (2006) A time course analysis of hypoxia, granulation tissue and blood vessel growth and remodelling in healing rat cutaneous incisional primary intention wounds. Wound Repair Regen. 14, 277-288

24. Muskhelishvili, L., Latendresse, J. R., Kodell, R. L., and Henderson, E. B. (2003) Evaluation of cell proliferation in rat tissues with BrdU, PCNA, Ki-67(MIB-5) immunohistochemistry and in situ hybridization for histone mRNA. J. Histochem. Cytochem. 51, $1681-1688$

25. Hewitson, T. D., Bisucci, T., and Darby, I. A. (2000) In situ end-labeling of fragmented DNA and the localization of apoptosis. Methods Mol. Biol. 123, 157-164

26. Oehmichen, M., Wietholter, H., and Wolburg, H. (1982) Enhanced phagocytic activity of lymph node macrophages after intranodular injection of autologous red blood cells. $Z$ Rechtsmed. 88, 285-296

27. Howard, C. V., and Reed, M. G. (1998) Unbiased Stereology: Bios Scientific Publishers, Oxford, UK

28. Lokmic, Z., Idrizi, R., Messina, A., Knight, K.R., Morrison, W., and Mitchell, G. (2004) Vascularisation of engineered constructs. In Encyclopedia of Biomaterials and Biomedical Engineering (Wnek, G. E., and Bowlin, G. L., eds) pp. 1750-1759, Marcel Dekker Inc., New York.

29. Van Hinsbergh, V. W., Collen, A., and Koolwijk, P. (2001) Role of fibrin matrix in angiogenesis. Ann. N. Y. Acad. Sci. 936, $426-437$

30. Shweiki, D., Itin, A., Soffer, D., and Kreshet, E. (1992) Vascular endothelial growth factor induced by hypoxia may mediate hypoxia-initiated angiogenesis. Nature 359, 843-845

31. Alenghat, F. J., and Ingber, D. E. (2002) Mechanotransduction: all signals point to cytoskeleton, matrix, and integrins. Sci. STKE 119, PE6

32. Ingber, D. (1991) Extracellular matrix and cell shape: potential control points for inhibition of angiogenesis. J. Cell. Biochem. 47, 236-241

33. Ichioka, S., Shibata, M., Kosaki, K., Sato, Y., Harii, K., and Kamiya, A. (1997) Effects of shear stress on wound-healing angiogenesis in the rabbit ear chamber. J. Surg. Res. 72, 29-35

34. Tanaka, Y., Sung, K. C., Tsutsumi, A., Ohba, S., Ueda, K., and Morrison, W. A. (2003) Tissue engineering skin flaps: which vascular carrier, arteriovenous shunt loop or arteriovenous bundle, has more potential for angiogenesis and tissue generation? Plast. Reconstr. Surg. 112, 1636-1644

35. Egginton, S., and Gerritsen, M. (2003) Lumen formation: in vivo versus in vitro observations. Microcirculation 10, 45-61

36. Carmeliet, P., Dor, Y., Herbert, J. M., Fukumura, D., Brusselmans, K., Dewerchin, M., Neeman, M., Bono, F., Abramovitch, R., Maxwell, P., et al. (1998) Role of HIF-lalpha in hypoxiamediated apoptosis, cell proliferation and tumour angiogenesis. Nature 394, 485-490

37. Darby, I. A., Bisucci, T., Pittet, B., Garbin, S., Gabbiani, G., and Desmouliere, A. (2002) Skin flap-induced regression of granulation tissue correlates with reduced growth factor and increased metalloproteinase expression. J. Pathol. 197, 117-127

38. Stupack, D. G., and Cheresh, D. A. (2003) Apoptotic cues from the extracellular matrix: regulators of angiogenesis. Oncogene $\mathbf{2 2}$ 9022-9029

Received for publication July 18, 2006. Accepted for publication September 14, 2006. 